\title{
Legal regulation of "green" agriculture in Russia: current state and prospects of development
}

\author{
Natalia Voronina, ${ }^{1, *}$, and Zhanna Shnorr ${ }^{2}$ \\ ${ }^{1}$ Kutafin Moscow State Law University (MSAL), Sadovaya-Kudrunskaya str., 9, 125993 Moscow, \\ Russia \\ ${ }^{2}$ Novosibirsk State University of Economics and Management (NSUEM), Kamenskaya str., 56, \\ 630099 Novosibirsk, Russia
}

\begin{abstract}
According to the Millennium Development Goals, approved by the UN in 2000 , it is necessary to eradicate hunger in the 21 st century, while solving the environmental problems that have accumulated over the past hundred years. The international community sees a way out in the development of a "green" economy, an integral part of which is agriculture. The current state of technology development enables the use of innovative methods of agricultural activities, including biotechnology. However, the consequences of their use for humans and the environment are completely unknown. Biotechnologies make it possible to obtain agricultural products with pre-defined characteristics, adapt their cultivation and production to unfavorable natural conditions, and increase labor productivity. But at the same time, the UN and FAO strategic planning documents note that produced agricultural products shall be safe for human health, and agricultural activities shall have a minimal impact on the environment. Therefore, the need for the formation and development of a model of "green" agriculture is justified at the international level. In Russia, attention is also paid to the production of products that are as safe as possible for both humans and the environment. At the same time, the current state of legal regulation of "green" agriculture does not allow us to speak about the formed effective model of legal regulation of the production of environmentally safe agricultural products. Legal problems and conflicts of the current legislation do not allow our country to take a competitive position in the international market of agricultural products. The purpose of this article is to provide a legal analysis of the current legislation and identify possible solutions to the legal problems of "green" agriculture, as well as to form a conceptual model of its legal regulation. Using the methods of comparative analysis, legal hermeneutics, and legal modeling, a legal analysis of the modern legal regulation of "green" agriculture is carried out and a conceptual model of its legal regulation is determined, based on which proposals for improving legislation in the considered sphere of public relations are formulated.
\end{abstract}

*Corresponding author: nvoroninamgua@yandex.ru 


\section{Introduction}

In the Address of the President of the Russian Federation to the Federal Assembly of the Russian Federation for 2015, it is noted that "it is necessary to set a task at the national level and by 2020 fully provide the domestic market with domestic food ... Russia can become the world's largest supplier of healthy, environmentally friendly, high-quality food" [1]. In 2019, the President of the Russian Federation gave the order "to create a protected brand of domestic clean, "green " products" [2], with an emphasis not only on the saturation of such products in the domestic market but also on their export to foreign markets. Production of environmentally friendly agricultural products requires a review of the organization of agricultural activities in terms of the ecological state of the natural resources used, technologies, fertilizers, etc. One of the necessary conditions is the effective legal regulation of "green" agriculture. However, the analysis of the current legal regulation enables to note its insufficient nature, gaps, and conflicts. There is a number of publications on the legal regulation of the organization of production of environmentally friendly agricultural products [3] and ensuring food security [4], but they are fragmentary, which does not allow us to approach the solution of legal problems on a comprehensive and systematic basis. It is necessary to define a conceptual model of legal regulation of "green" agriculture, based on which proposals for improving the current legislation will be developed.

\section{Methods and types}

The conducted research is carried out based on a number of methods: comparative analysis, legal hermeneutics, legal modeling. The comparative analysis of the scientific literature, current Russian legislation, international documents, and the practice of agricultural producers revealed the legal problems of the formation of "green" agriculture in Russia. They include the lack of legal regulation, legal conflicts, lack of a number of state standards, and non-compliance with international environmental and legal requirements for agricultural products. The method of legal hermeneutics allowed us to interpret the current legal norms to identify the most problematic legal aspects of the development of "green" agriculture. The method of legal modeling allowed us to define a conceptual model of legal regulation of "green" agriculture and form possible prospects for its development.

\section{Results and discussion}

The model of legal regulation shall mean "a set of essential features and characteristics of external and internal legal influence on the behavior of participants in a certain sphere of public relations through interrelated legal means, methods, and ways aimed at effectively achieving goals by implementing direct and indirect tasks" [5, p. 18]. On the internal side, it is a system of essential features and characteristics of the legal impact on public relations. On the external side, it is a set of normative legal acts and legal norms regulating public relations in a certain area.

"Green" agriculture is the production of agricultural products of two types: organic and with improved characteristics. 


\subsection{Organic products}

According to a number of scientists, environmentally friendly agricultural products are exclusively organic products [6]. However, traditional agriculture can also be ecological if environmental requirements are met [7].

According to the concept of sustainable development and creating a "green" economy, organic agriculture is a sustainable model of agricultural production. Its main principle is "production and turnover of organic products without causing harm to human health and environmental disturbance. [8]. In November 2017, the International Federation Organic Agriculture Movements (IFOAM) has decided to move to a new stage of development Organic 3.0. Now organic agriculture should focus on "solving global problems, such as mitigating the negative effects of climate change, preserving biodiversity, and fighting hunger" [9].

The legal regulation of organic production in Russia developed gradually. At the initial stage, only state standards for the production, storage, and transportation of organic products, certification, and labeling were adopted. Their subordinate level, and most importantly, their fragmentary nature, did not allow for comprehensive legal regulation of the production and turnover of organic products. At the same time, in foreign countries, it was the regulatory legal acts of the level of the law that regulated similar legal relations, which allowed foreign countries to take a leading position in the world food market.

Our comparative analysis allowed us to conclude that 87 foreign countries have a corresponding law. At the same time, two legal approaches can be distinguished - in some countries it is the law on organic agriculture, in others - the law on organic products [10, p. $35]$.

These factors led to the adoption of Federal Law No. 280-FZ of August 3, 2018 "On Organic Products and Amendments to Certain Legislative Acts of the Russian Federation" (hereinafter referred to as the Law).

Domestic Law is a kind of "golden mean" between the laws on organic agriculture and organic products. First of all, it supplemented the conceptual framework with definitions of organic agriculture and organic products. The literature notes that the definition of these concepts allows us to assess "the risks that arise from scrupulous producers in connection with the properties of such high-quality products that have a positive impact on human health and the conditions of its production that contribute to improving the environment and solving a number of social problems" [11]. Unscrupulous producers may be tempted to position their products as organic for no reason. Therefore, one of the tasks of legal regulation is to create legal mechanisms aimed at suppressing unfair competition and consumer fraud. These tools include entering information about the producer of organic products and the products themselves in a special register, as well as labeling organic products. Similar mechanisms are envisaged by almost all foreign countries. Therefore, the application of this Law is impossible to imagine without a number of bylaws, which are also part of the model of legal regulation of organic products. In 2019, several orders of the Ministry of Agriculture of the Russian Federation were approved, defining the procedure for maintaining the unified state register of organic producers and the procedure for using a graphic image (sign) of organic products. Also, various standards in the field of organic production are an integral part of the legal regulation of organic products.

It may seem that the legal regulation of the production and turnover of organic products can be considered complete, but there are still a number of unresolved legal issues related to organic products. They are as follows: unification by common legal requirements of all stages of the turnover of organic products without taking into account their features [12, $\mathrm{p}$. 87]; absence of an indication of the application of the Law to beekeeping products; definition of organic agriculture without an indication of the use of innovative technologies, modern scientific and technical developments, conservation of biodiversity [12, p. 88] 
(main drawback of this definition is the lack of an indication of the systemic nature of organic agriculture [13]); reference nature of the norms on certification of organic products; lack of powers of the Russian Federation, constituent entities of the Russian Federation and municipalities in the field of organic products turnover, etc. This does not allow the active development of the market for organic products (as of May 18, 2021, only 64 organic producers were listed in the register).

\subsection{Agricultural products with improved characteristics}

In contrast to organic products, agricultural products with improved characteristics are products and raw materials whose quality and consumer characteristics meet the requirements of the current legislation on agricultural products with improved characteristics. This legal approach is fixed in the Draft Law No. 1087686-7 "On Agricultural Products, Raw Materials and Food with Improved Characteristics" (hereinafter referred to as the Draft Law). It was developed by the Ministry of Agriculture of the Russian Federation and was originally referred to as the Draft Federal Law "On Agricultural Products, Raw Materials and Food with Improved Environmental Characteristics and On Amendments to the Federal Law "On the Development of Agriculture"". Its key definition was the concept of "improved environmental characteristics" as indicators of the quality and safety of agricultural products, raw materials, and food, taking into account environmental factors defined by standards in the field of turnover of agricultural products with improved environmental characteristics. In this form, the project has caused a flurry of criticism from the professional community. In particular, representatives of the Organic Agriculture Union of Russia noted the main shortcomings of the draft law: no relevant international requirements criteria of environmentally friendly products; no provided line of environmentally friendly products of international standards of environmental performance based on ISO 14000 standards; certification recognized on the territory of foreign countries; no criteria for assigning products to environmentally friendly, etc. [14] All this will not allow domestic products to enter foreign markets. Therefore, it is necessary to have a legal regulation that is identical to the regulation of the production of agricultural products with improved characteristics in foreign countries. In this regard, the title of the draft law and its content have been adjusted. Currently, it has been adopted in the second reading, and the text of the draft law has been prepared for the third reading.

The draft law provides a number of requirements for the production, storage, transportation, and sale of improved agricultural products (Article 4). Legal instruments aimed at identifying agricultural products with improved characteristics include: maintaining a register and labeling products.

An integral part of the legal regulation of the production and turnover of agricultural products with improved characteristics are the GOST standards adopted during 2019 (6 GOST standards in total). In particular, the term "agricultural products with improved environmental characteristics" is used in all these GOST standards. Therefore, if the law is adopted in a prepared version after it enters into legal force, it is likely that these standards will need to be at least renamed and at most to change the content. In addition, it is necessary to adopt a number of subordinate legal acts regulating the maintenance of the register of producers of agricultural products with improved characteristics, as well as the procedure for labeling these products.

Thus, "green" agriculture is a promising direction of domestic agriculture. The production of organic products and agricultural products with improved characteristics allows not only to ensure the food security of Russia, but also to increase the competitiveness of domestic agricultural products in the international food market. 


\section{Conclusions}

In conclusion, it should be noted that the development of "green" agriculture is impossible to imagine without appropriate legal regulation. If the issue of regulating the production of organic products is relatively resolved, but the issue of the production of agricultural products with improved characteristics is yet to be dealt with. We believe that the improvement of legal regulation in this area of public relations should be carried out based on a conceptual model of legal regulation of "green" agriculture. On the internal side, the conceptual model of legal regulation is a system of essential features and characteristics of the legal impact on internal and external relations for the production, storage, transportation, sale of organic products and agricultural products with improved characteristics, carried out in compliance with the requirements established by the current legislation, aimed at ensuring food security and increasing the export of agricultural products. On the external side, the conceptual model of legal regulation is a set of regulatory legal acts and legal norms aimed at regulating public relations in the field of production, storage, transportation, and sale of organic products and agricultural products with improved characteristics.

\section{References}

1. Address of the President of the Russian Federation to the Federal Assembly dated 03.12.2015 "Address of the President of the Russian Federation", Russian newspaper (2015)

2. Address of the President of the Russian Federation to the Federal Assembly dated 20.02.2019 "Address of the President to the Federal Assembly", Parliamentary Newspaper (2019)

3. A. P. Anisimov, O. V. Popova, Loopholes in the Russian Legislation, 3, 59 (2020)

4. L. V. Voronina, M. G. Yurkevich, IOP Conf. Ser.: Earth Environ. Sci., 539, 012056 (2020)

5. N. P. Voronina, Agrarian and Land Law, 7, 17 (2020)

6. A. P. Anisimov, O. V. Popova, Bulletin of the Yanka Kupala Grodno State University. Ser. 4. Jurisprudence, 7(4), 60 (2017)

7. E. Schulze, N. V. Pakhomova, N. Yu. Nesterenko, Yu. V. Krylova, K. K. Rikhter, Bulletin of the Saint Petersburg University. Economy, 4, 4 (2015)

8. B. A. Voronin, Agrarian Bulletin of the Urals, 9, 80 (2013)

9. A. Kh. Zanilov, O. S. Melentyeva, A. M. Nakaryakov, Scientific and methodological recommendations for agricultural consultants "Organization of organic agricultural production in Russia" (2019) https://soz.bio

10. N. P. Voronina, Agrarian and Land Law, 6, 34 (2019)

11. A. V. Mikhailov, Competition Law, 3, 37 (2019)

12. N. Avarsky, V. Taran, Agroindustrial Complex: Economics, Management, 10, 88 (2018)

13. N. P. Voronina, Russian Legal System in the Conditions of the Fourth Industrial Revolution. XVI International Scientific and Practical Conference, 2, 143 (2019)

14. Information from the website of the Organic Agriculture Union of Russia (2019) https://soz.bio 